\title{
Anatomia foliar de Corymbia calophylla (Lindl.) K.D.Hill \& L.A.S. Johnson, Myrtaceae
}

\author{
Patrícia Mathias Döll-Boscardin, ${ }^{1}$ Paulo Vitor Farago, ${ }^{*, 2}$ Josiane Padilha de Paula, ${ }^{2}$ \\ Tomoe Nakashima ${ }^{1,3}$
}

\author{
${ }^{1}$ Programa de Pós-graduação em Ciências Farmacêuticas da Universidade Federal do Paraná, \\ Av. Pref. Lothário Meissner, 632, 80210-170 Curitiba-PR, Brasil, \\ ${ }^{2}$ Departamento de Ciências Farmacêuticas, Universidade Estadual de Ponta Grossa, Av. Carlos Cavalcanti, 4748, \\ 84030-900 Ponta Grossa-PR, Brasil, \\ ${ }^{3}$ Departamento de Farmácia, Universidade Federal do Paraná, Av. Pref. Lothário Meissner, 632, 80210-170 \\ Curitiba-PR, Brasil.
}

\begin{abstract}
RESUMO: Corymbia pertence à família Myrtaceae e envolve mais de 100 espécies arbóreas. Particularmente, a espécie Corymbia calophylla (Lindl.) K.D.Hill \& L.A.S. Johnson é um dos taxa transferidos de Eucalyptus para Corymbia, com utilização para a fabricação de mobiliário requintado e para o tratamento de disfunções digestivas, segundo a medicina tradicional australiana. O presente trabalho teve por objetivo avaliar as características anatômicas da folha de C. calophylla, a partir de espécimes coletados na Embrapa Florestas (Colombo-PR, Brasil). As análises anatômicas foram conduzidas a partir dos métodos usuais de microscopia fotônica e microscopia eletrônica. A anatomia foliar revelou a presença de estômatos anomocíticos na face abaxial da folha, mesofilo dorsiventral e nervura mediana com cavidades secretoras inseridas no sistema vascular. Em secção transversal, o pecíolo apresentou formato plano-convexo. Na estrutura anatômica do limbo foliar, da nervura mediana e do pecíolo foram observadas cavidades secretoras contendo material de natureza lipofílica, além de idioblastos de conteúdo fenólico. Alguns idioblastos contendo drusas de oxalato de cálcio foram também observados no parênquima da nervura mediana de C. calophylla.
\end{abstract}

Unitermos: Cavidades secretoras, Corymbia, Eucalyptus, Myrtaceae, farmacobotânica.

\begin{abstract}
Leaf anatomy of Corymbia calophylla (Lindl.) K.D. Hill e L.A.S. Johnson (Myrtaceae)" Corymbia, a genus of Myrtaceae, shows more than 100 tree species. In particular, Corymbia calophylla (Lindl.) K.D.Hill \& L.A.S. Johnson is one of the taxa changed from Eucalyptus to Corymbia. C. calophylla has been used for fine furniture and for treating digestive upsets according to the Australian traditional medicine. The goal of this paper was to study the anatomical data of leaves from C. calophylla. The botanical material was collected from Embrapa Forest (Colombo-PR, Brazil). The anatomical analyses were performed by the usual light and scanning microtechniques. Anomocytic stomata were observed on the abaxial surface. The foliar blade showed dorsiventral mesophyll. Midrib having secretory cavities included on the vascular system was seen. In transection, a plane-convex petiole was found. Secretory cavities with oil content were verified in the anatomical structures of the foliar blade, midrib and petiole, as well as idioblasts with phenolic substances. Some calcium oxalate druses were observed in parenchymatous tissue of the midrib of C. calophylla.
\end{abstract}

Keywords: Corymbia, Eucalyptus, Myrtaceae, pharmacobotany, secretory cavities.

\section{INTRODUÇÃO}

Myrtaceae Juss. possui cerca de 3500 espécies, com distribuição ampla pelos continentes, excetuando a Antártica (Gressler et al., 2006). No Brasil, esse grupo taxonômico tem sido considerado um dos principais representantes de Magnoliopsida, em razão da grande diversidade de taxa e pelo papel relevante na fitossociologia das florestas do Sul e Sudeste do país (Cruz \& Kaplan,
2004). Esses mesmos autores indicaram que cerca de $70 \%$ das plantas pertencentes a essa família têm potencial terapêutico, sendo utilizadas na medicina tradicional em distúrbios gastrointestinais, estados hemorrágicos e doenças infecciosas. Além disso, diversos trabalhos científicos contemporâneos têm respaldado o uso popular de espécimes dos diversos gêneros de Myrtaceae, por meio de diferentes investigações farmacognósticas, relacionadas aos aspectos botânicos (Paula et al., 2008; 
Donato \& Morretes, 2007; Cardoso \& Sajo, 2004; Soffiatti \& Angyalossy-Alfonso, 1999), fitoquímicos (Wannes et al., 2008; Cole et al., 2007; Hussein et al., 2007; Migliato et al., 2007; Guo \& Yang, 2006; Oliveira et al., 2006) e de atividades biológicas (Salvagnini et al., 2008; Biavatti et al., 2007; Kreuger et al., 2007; Medeiros et al., 2007; Oliveira et al., 2007; Serafin et al., 2007; Alves et al., 2006; Amaral et al., 2006; Apel et al., 2006; Barbosa Filho et al., 2006; Bezerra et al., 2006; Gondim et al., 2006; Lima et al. 2006).

Corymbia, estabelecido a partir de 1995 como um novo grupo taxonômico de Myrtaceae (Hill \& Johnson, 1995), é composto por aproximadamente 113 espécies arbóreas anteriormente incluídas em Eucalyptus L'Hér. No entanto, os estudos relativos às atividades biológicas desse grupo têm sido efetuados, especialmente, envolvendo a espécie Corymbia citriodora (Hook.) K.D. Hill e L.A.S. Johnson. Jirovetz et al. (2007) avaliaram a atividade antioxidante do óleo essencial das folhas de $C$. citriodora por diversos modelos de atividade antioxidante, concluindo que essa essência atua como um sequestrador do radical hidroxila de forma superior à quercetina, quando avaliada pelo método da 2-D-desoxirribose (Halliwell et al., 1987). Medice et al. (2007) avaliaram o efeito de diferentes óleos essenciais sobre o fungo Phakopsora pachyrhizi e observaram que o óleo essencial de C. citriodora teve efeito direto na germinação de urediniósporos desse microrganismo, sendo capaz de reduzir a severidade da ferrugem-da-soja. Em pesquisa realizada com plantas tradicionalmente usadas como repelentes de mosquitos no oeste do Quênia (Seyoum et al., 2002), foi verificado que C. citriodora apresentou a maior repelência.

C. calophylla é uma árvore de aproximadamente $40 \mathrm{~m}$ de altura, natural da região oeste da Austrália, com exemplares aclimatados na região Sul do Brasil. Esse táxon é popularmente conhecido como marri pelos aborígenes australianos, sendo tradicionalmente recomendado para disfunções digestivas (Adams, 2006), fato assemelhado aos dados etnofarmacológicos atribuídos para outras espécies de Myrtaceae da flora brasileira (Cruz \& Kaplan, 2004). Além disso, a madeira de C. calophylla tem sido apreciada e aproveitada na fabricação de mobiliário requintado (Barrow, 2007). Com relação ao óleo essencial de C. calophylla, dados restritos têm sido verificados na literatura, com pouco detalhamento acerca das estruturas secretoras presentes na espécie. Baker \& Smith (1920) verificaram um rendimento de $0,5 \%$ para o óleo essencial de C. calophylla, indicando a presença de $\alpha$-pineno, provavelmente como o constituinte majoritário.

$\mathrm{O}$ presente trabalho tem por objetivo avaliar a anatomia das folhas de C. calophylla, com o propósito de subsidiar outros estudos farmacognósticos e de controle da qualidade.

\section{MATERIAL E MÉTODOS}

As folhas adultas de Corymbia calophylla (Lindl.) K.D.Hill \& L.A.S. Johnson (variedade rósea), Myrtaceae, a partir do quarto nó, foram coletadas de espécimes previamente determinados, localizados na Empresa Brasileira de Pesquisa Agropecuária (Embrapa Florestas), no município de Colombo (latitude 25 20' $\mathrm{S}$, longitude $49^{\circ} 14^{\prime} \mathrm{W}$ e altitude de $920 \mathrm{~m}$ ), na região metropolitana de Curitiba, estado do Paraná, durante o outono (junho de 2008). A exsicata foi depositada no Herbário da Universidade Estadual de Ponta Grossa, com o registro HUPG 14809, após a determinação botânica pelo taxonomista A. A. Carpanezzi.

A fixação das folhas para a obtenção das lâminas permanentes e semipermanentes foi realizada com FAA 70 (Johansen, 1940), sendo posteriormente armazenadas em álcool etílico a 70\% (v/v). Para a preparação das lâminas permanentes, o material foi desidratado em série etanólica crescente e diafanizado em xilol. A infiltração foi feita em parafina (Johansen, 1940), em estufa a $60^{\circ} \mathrm{C}$. As secções transversais da porção central e mediana do limbo foliar e do pecíolo foram obtidas a partir dos blocos parafinados, em micrótomo de rotação Leica RM 2025, com 10 e 12 m de espessura. As secções foram hidratadas, distendidas nas lâminas e secas em mesa térmica a $40{ }^{\circ} \mathrm{C}$. Para a coloração foi empregado azul de toluidina a 0,05\% (Sakai, 1973) ou azul de astra a 0,5\% mais fucsina básica a 0,0125\% (Luque et al., 1996; Roeser, 1972). Como meio de montagem foi usado o bálsamo do Canadá sintético. Para a montagem das lâminas semipermanentes, foi utilizado o método de Berlyn \& Miksche (1976). Além de secções transversais e longitudinais da porção central e mediana do limbo foliar e do pecíolo, foram realizadas secções paradérmicas da face adaxial e da face abaxial das folhas. As secções foram feitas à mão livre com posterior coloração com azul de toluidina a 0,05\% (Haddad, 1989) ou fucsina básica a 0,0125\% mais azul de astra a 1\% (Brito \& Alquini, 1996). Para a montagem das lâminas foi utilizada glicerina a $50 \%$ (v/v) em água purificada. Em seguida, foi efetuada a lutagem das lâminas com esmalte de unha incolor.

Testes microquímicos foram também executados a partir de folhas recentemente coletadas de C. calophylla com as soluções de Sudan III para evidenciar substâncias lipofílicas (Sass, 1951), lugol para amido (Berlyn \& Miksche, 1976), cloreto férrico para compostos fenólicos (Johansen, 1940), floroglucina clorídrica para lignina (Foster, 1949) e ácido sulfúrico para cristais de oxalato de cálcio (Oliveira \& Akisue, 1997). Os registros fotográficos foram obtidos por meio do fotomicroscópio Olympus CX31, sendo que as escalas micrométricas foram fotografadas e ampliadas nas mesmas condições ópticas.

Para a análise ultraestrutural das superfícies adaxial e abaxial da lâmina foliar, as amostras foram fixadas em FAA 70 e desidratadas em série etanólica crescente (Souza, 1998). Após a montagem em suporte 
metálico, os fragmentos da região mediana das folhas foram submetidos à metalização com ouro em aparelho Shimadzu IC-50. As eletromicrografias foram realizadas em microscópio eletrônico de varredura Shimadzu SSX550 Superscan $(15 \mathrm{kV})$. O registro das imagens ocorreu pela utilização do software específico.
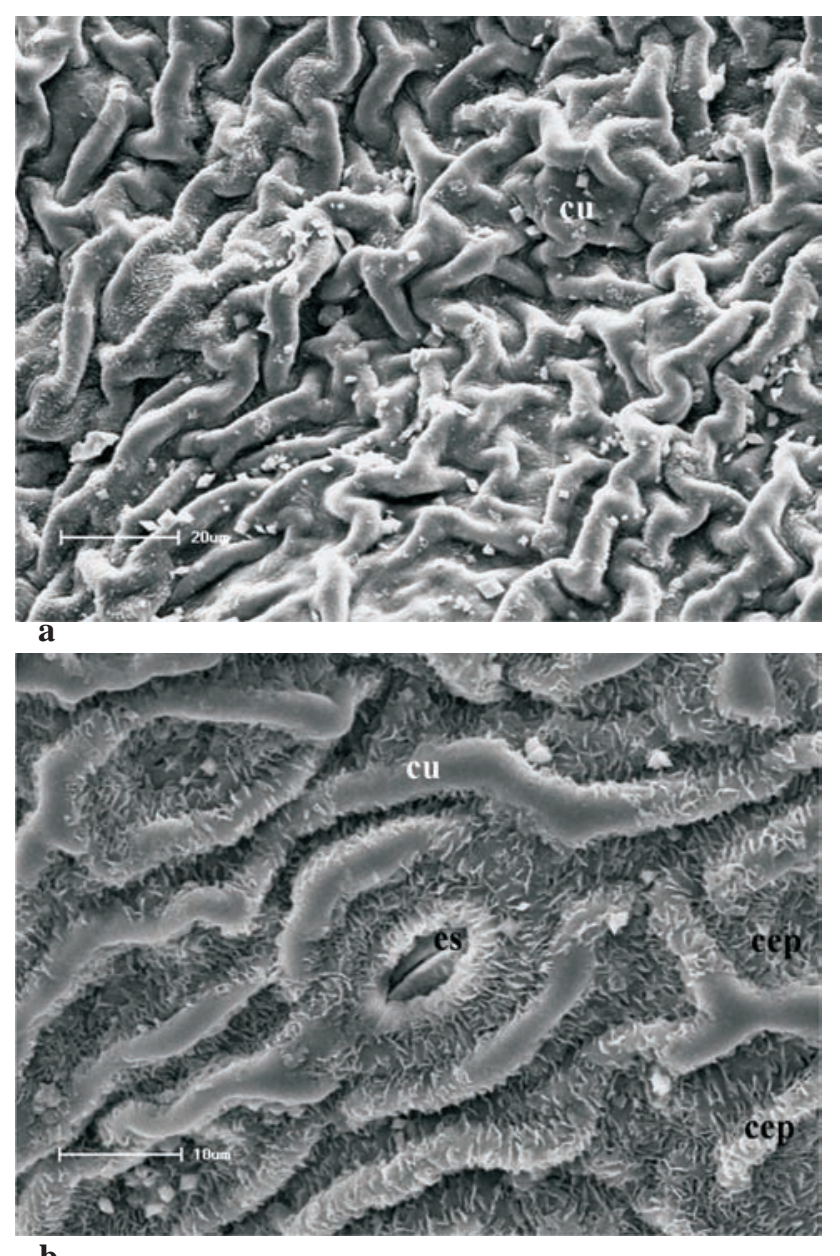

b

Figura 1. Eletromicrografias das superfícies da folha de $C$. calophylla, a. Face adaxial, b. Face abaxial, revelando cera epicuticular (cep), cutícula (cu) e estômato (es).

\section{RESULTADOS}

Em vista frontal, as folhas de C. calophylla revelaram estômatos (Figura $1 b$ ) apenas na face abaxial, sem a presença de tricomas. Os estômatos foram classificados como do tipo anomocítico. A cutícula apresentou uma ornamentação com aspecto ondulado e sinuoso (Figuras 1a e 1b) em ambas as faces, particularmente mais acentuado na face adaxial. Na face abaxial, foi evidenciada cera epicuticular disposta como pequenas placas perpendiculares nas regiões em depressão e em algumas porções mais superficiais.

Em secção transversal, os referidos estômatos foram verificados no mesmo nível das células epidérmicas. Em ambas as faces, foi constatada a presença de epiderme uniestratificada (Figura 2), recoberta por uma cutícula delgada. Um estrato contínuo de células idioblásticas, com conteúdo fenólico foi evidenciado subjacentemente à epiderme adaxial. $\mathrm{O}$ mesofilo foi classificado como dorsiventral (Figura 2), sendo composto por parênquima clorofiliano paliçádico, formado por células alongadas dispostas em dois ou três estratos celulares. No parênquima clorofiliano esponjoso, foram observados de cinco a sete estratos de células frouxamente distribuídas. Feixes vasculares de médio e de pequeno porte (Figura 2) foram localizados na região limítrofe entre o parênquima paliçádico e o parênquima esponjoso. Esses elementos de condução foram guarnecidos por calotas de natureza esclerenquimática (Figura 2), sendo que idioblastos comparativamente maiores do que as células parenquimáticas e de conteúdo fenólico foram particularmente visualizados, permitindo a comunicação com os elementos epidérmicos. No mesofilo, também foram observadas cavidades secretoras (Figura 2), situadas mais próximas à face adaxial do limbo foliar. As cavidades secretoras, por meio dos ensaios microquímicos, indicaram a presença de conteúdo de caráter lipofílico.

A nervura mediana, em secção transversal, revelou formato plano-convexo (Figura 3a). As células epidérmicas uniestratificadas apresentaram a parede periclinal externa de formato levemente lenticular, em ambas as faces, e com cutícula delgada. Subjacentemente à epiderme de ambas as faces, foi visualizado um único estrato de colênquima angular. O parênquima fundamental revelou células comparativamente maiores, arredondadas e de parede delgada, sendo que foi observada a presença de um elevado número de idioblastos contendo substâncias de natureza fenólica (Figura 3b). A região perivascular foi constituída por uma bainha esclerenquimática descontínua (Figuras 3a). O sistema vascular (Figura 3a) demonstrou a presença de feixes de aspecto bicolateral, com o xilema disposto de forma paralela ao floema externo e floema interno. Duas cavidades secretoras (Figura 3a), com conteúdo de natureza lipofílica, foram verificadas internamente ao sistema vascular. Na região de parênquima foi visualizada ainda, a presença de idioblastos contendo drusas de oxalato de cálcio (Figura 3b).

Em secção transversal, o pecíolo revelou um formato plano-convexo (Figura 4). As células epidérmicas uniestratificadas (Figura 4) foram revestidas por cutícula de espessamento comparativamente semelhante. Na região cortical, foram observados de três a seis estratos de colênquima angular e vários estratos de células parenquimáticas. O sistema vascular foi envolto por uma bainha esclerenquimática (Figura 4), em diferentes estágios de lignificação. O sistema vascular (Figura 4) apresentou organização cêntrica, do tipo bicolateral. A região medular foi composta por poucas células parenquimáticas (Figura 4). Na região subepidérmica, foram verificadas cavidades secretoras (Figura 4), semelhantes àquelas relatadas para 
o limbo foliar. Na região cortical, foram evidenciados diversos idioblastos, de conteúdo fenólico, e algumas células contendo drusas. Além disso, cavidades secretoras foram visualizadas junto ao sistema vascular (Figura 4).

\section{DISCUSSÃO}

Considerando os resultados relatados em artigos anteriores, particularmente para Eugenia brasiliensis Lam. (Donato \& Morretes, 2007) e Pimenta pseudocaryophyllus (Gomes) L.R. Landrum (Paula et al., 2008), é possível afirmar que a avaliação anatômica das folhas de $C$. calophylla revela características comuns a outras espécies de Myrtaceae. Entretanto, a organização anatômica, associada à descrição de elementos estruturais específicos, como as estruturas secretoras descritas, contribuem de forma determinante para a identificação dessa espécie medicinal pertencente ao gênero Corymbia.

De acordo com Cronquist (1981) e Metcalfe \& Chalk (1979), os estômatos são usualmente anomocíticos em Myrtaceae, com exceção de algumas poucas espécies, que podem apresentar estômatos paracíticos, e geralmente ocorrem em ambas as faces do limbo foliar (Tuffi Santos et al., 2008). A presença de estômatos do tipo anomocítico em C. calophylla concorda com a literatura, porém estando presentes somente na superfície abaxial do limbo foliar.

A partir da análise da cutícula, é possível estabelecer que C. calophylla possui uma ornamentação ondulada e sinuosa em ambas as faces. Nesse gênero, a cutícula pode apresentar superfícies liso-delgadas, sinuosas, crenadas, digitais ou espessadas (Metcalfe \& Chalk, 1979). Notadamente, cera epicuticular caracterizada por pequenas placas perpendiculares compõe as regiões em depressão e algumas porções mais superficiais da face abaxial. A possibilidade de usar a morfologia da cera epicuticular na classificação e na diagnose tem sido extensivamente investigada em alguns taxa, especialmente para Eucalyptus (Metcalfe \& Chalk, 1979). Em estudo morfoanatômico de Eugenia brasiliensis (Donato \&
Morretes, 2007) foi observado que a superfície revelou aspecto liso, sem ornamentações, diferindo do obtido para C. calophylla.

Com relação à anatomia do mesofilo, é possível evidenciar que o limbo foliar de C. calophylla demonstra uma organização dorsiventral. Tuffi Santos et al. (2008), ao analisar o mesofilo de seis clones de Eucalyptus grandis W. Hill ex Maiden submetidos ao herbicida glifosato, constataram que esse táxon revela uma estrutura dorsiventral, composto de um parênquima esponjoso proeminente e um a dois estratos de parênquima paliçádico. Donato \& Morretes (2007) também relataram a existência de um mesofilo dorsiventral para a espécie Eugenia brasiliensis, todavia com uma tendência à isobilateralidade.

Myrtaceae comumente revela a presença de drusas de oxalato de cálcio, isoladas ou agrupadas, em células presentes no tecido parenquimatoso (Cronquist, 1981). Donato \& Morretes (2007) registraram a presença de idioblastos contendo drusas de oxalato de cálcio no mesofilo de Eugenia brasiliensis. No estudo anatômico de C. calophylla, idioblastos contendo drusas, em pequeno número, integram a região parenquimática da nervura mediana, não sendo visualizados na região de mesofilo.

Uma característica peculiar para Myrtaceae é a presença de cavidades secretoras, geralmente esquizolisígenas, indistintamente em ambas as faces, alinhadas com o epitélio, quando do desenvolvimento inicial do órgão vegetal (Metcalfe \& Chalk, 1979). Para Eucalyptus globulus Labill., Johnson (1926) verificou a presença de elevado número de cavidades secretoras, quase sempre com conteúdo de natureza oleosa, conferindo aspecto translúcido para as folhas jovens e adultas. As cavidades secretoras observadas na espécie $C$. calophylla têm características concordantes com as descritas para a família e para o gênero Eucalyptus, exceto por se encontrarem posicionadas mais próximas à face adaxial do limbo foliar.

Segundo Cronquist (1981) e Metcalfe \& Chalk

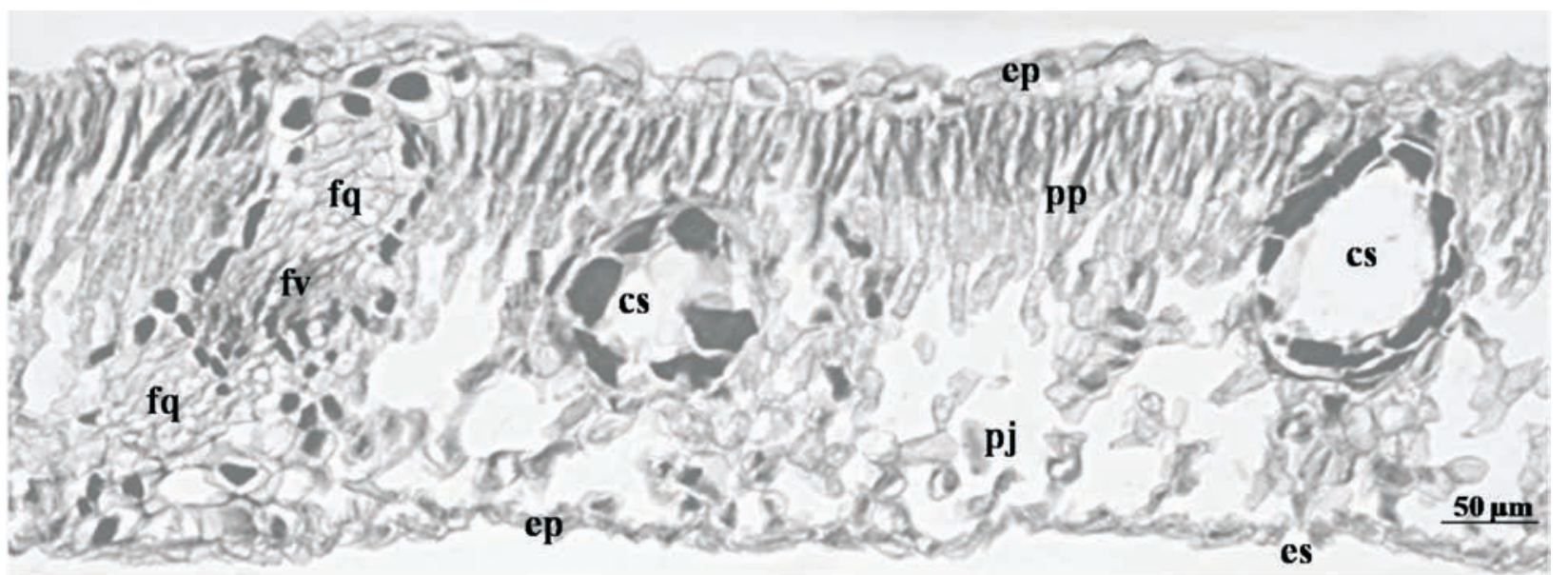

Figura 2. Secção transversal da folha de C. calophylla, aspecto geral destacando cavidade secretora (cs), epiderme (ep), estômato (es), feixe vascular (fv), fibras esclerenquimáticas (fq), parênquima esponjoso (pj) e parênquima paliçádico (pp). 
(1979), o pecíolo das Myrtaceae apresenta sistema vascular bicolateral. Paula et al. (2008) constataram que os feixes vasculares no pecíolo de $P$. pseudocaryophyllus estão organizados na forma de arco, do tipo bicolateral. Para o pecíolo de $C$. calophylla, foram verificadas características anatômicas em conformidade com a literatura, sendo que o sistema vascular único, de organização cêntrica e bicolateral, revela a presença particular de duas a três cavidades secretoras, internas ao sistema condutor.

Dessa forma, de importância farmacognóstica, a espécie analisada indicou elevado número de cavidades secretoras de conteúdo lipofílico na região de limbo foliar e de pecíolo; cavidades secretoras infundidas junto ao sistema vascular da nervura mediana e do pecíolo; idioblastos contendo drusas de oxalato de cálcio na região parenquimática da nervura mediana; além de expressivo número de células com conteúdo de natureza fenólica compondo a anatomia de C. calophylla. Essas informações particulares, quando analisadas em conjunto, respaldam o controle anatômico da qualidade para a espécie em estudo.

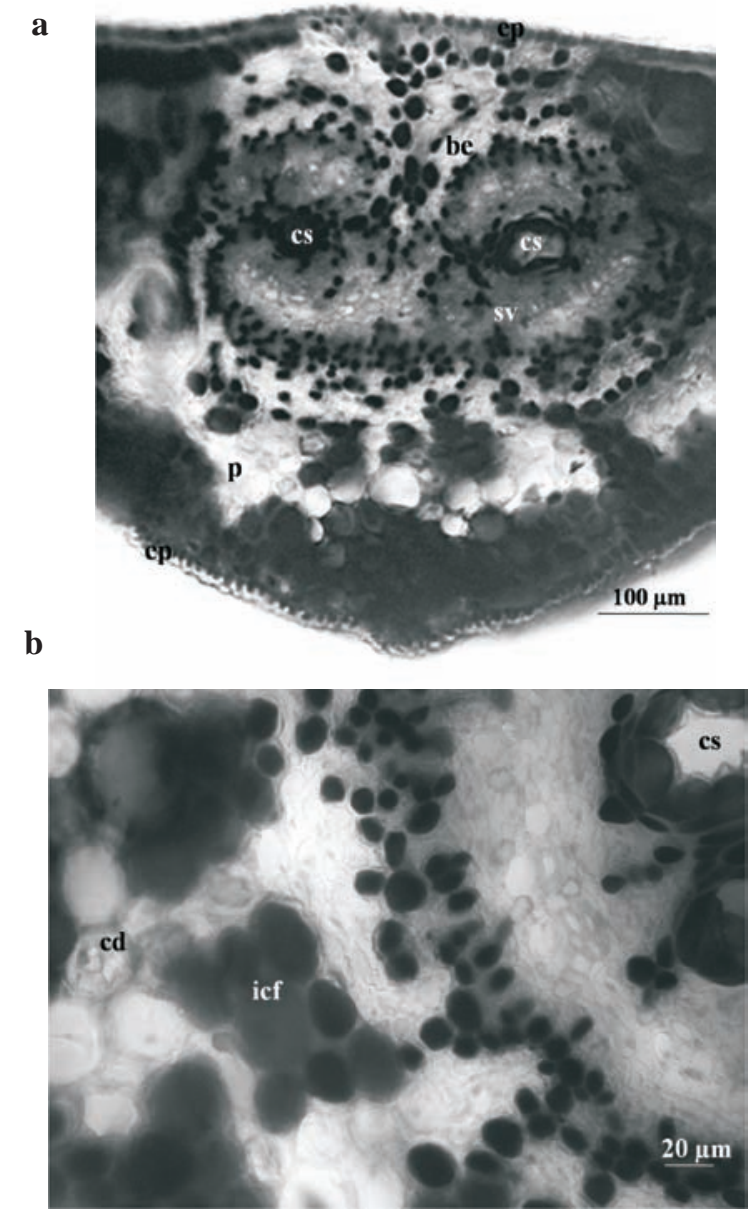

Figura 3. Secção transversal da nervura mediana da folha de $C$. calophylla, a. aspecto geral, indicando bainha esclerenquimática (be), cavidade secretora (cs), epiderme (ep), parênquima (p) e sistema vascular (sv), b. em destaque, a presença de cavidade secretora (cs), cristal do tipo drusa (cd) e idioblasto com composto fenólico (icf).

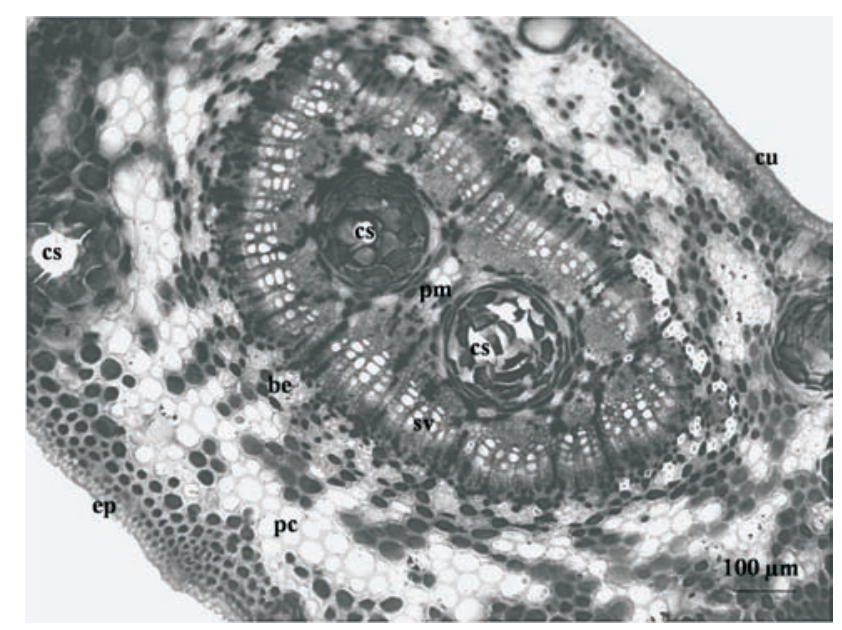

Figura 4. Secção transversal do pecíolo de C. calophylla, mostrando bainha esclerenquimática (be), cavidade secretora (cs), cutícula (cu), epiderme (ep), parênquima cortical (pc), parênquima medular (pm) e sistema vascular (sv).

\section{AGRADECIMENTOS}

Os autores agradecem ao Centro Nacional de Pesquisa de Florestas (CNPF) da Empresa Brasileira de Pesquisa Agropecuária (Embrapa), pelo material botânico cedido para a realização deste estudo, e à Coordenação de Aperfeiçoamento de Pessoal de Nível Superior (CAPES), pelo apoio financeiro.

\section{REFERÊNCIAS}

Adams PK 2006. Immanessence. Toodyay: Phillip Adams.

Alves PM, Leite, PHAS, Pereira, JV, Pereira, LF, Pereira MSV, Higino JS, Lima EO 2006. Atividade antifúngica do extrato de Psidium guajava Linn. (goiabeira) sobre leveduras do gênero Candida da cavidade oral: uma avaliação in vitro. Rev Bras Farmacogn 16: 192-196.

Amaral FMM, Ribeiro MNS, Barbosa-Filho JM, Reis AS, Nascimento FRF, Macedo RO 2006. Plants and chemical constituents with giardicidal activity. Rev Bras Farmacogn 16 (Supl.): 696-720.

Apel MA, Sobral M, Henriques AT 2006. Composição química do óleo volátil de Myrcianthes nativas da região sul do Brasil. Rev Bras Farmacogn 16: 402-407.

Baker RT, Smith HG 1920. A research on the Eucalypts. Sydney: NSW Govt Printer.

Barbosa-Filho JM, Medeiros KCP, Diniz MFFM, Batista LM, Athayde-Filho PF, Silva MS, Cunha EVL, Almeida JRGS, Quintans-Júnior LJ 2006. Natural products inhibitors of the enzyme acetylcholinesterase. Rev Bras Farmacogn 16: 258-285.

Barrow J 2007. Corymbia calophylla. Association of Societies for Growing Australian Plants. Disponível em http:// asgap.org.au/c-cal.html, acessada em junho de 2008.

Berlyn GP, Miksche JP 1976. Botanical microtechnique and cytochemistry. Ames: Iowa State University. 
Bezerra JL, Costa GC, Lopes TC, Carvalho ICDS, Patrício FJ, Sousa SM, Amaral FMM, Rebelo JMM, Guerra RNM, Ribeiro MNS, Nascimento FRF 2006. Avaliação da atividade leishmanicida in vitro de plantas medicinais. Rev Bras Farmacogn 16 (Supl.): 631-637.

Biavatti MW, Marensi V, Leite SN, Reis A 2007. Ethnopharmacognostic survey on botanical compendia for potential cosmeceutic species from Atlantic Forest. Rev Bras Farmacogn 17: 640-653.

Brito JFA, Alquini Y 1996. A new method for staining botanical material embedded in glycol methacrylate (GMA). Arq Biol Tecnol 39: 949-951.

Cardoso CMV, Sajo MG 2004. Vascularização foliar e a identificação de espécies de Eugenia L. (Myrtaceae) da bacia hidrográfica do Rio Tibagi, PR. Rev Bras Bot 27: 47-54.

Cole RA, Haber WA, Setzer WN 2007. Chemical composition of essential oils of seven species of Eugenia from Monteverde, Costa Rica. Biochem Syst Ecol 35: 877886.

Cronquist A 1981. An integrated system of classification of flowering plants. New York: Columbia University Press.

Cruz AVM, Kaplan MAC 2004. Uso medicinal de espécies das famílias Myrtaceae e Melastomataceae no Brasil. Floresta e Ambiente 11: 47-52.

Donato AM, Morretes BL 2007. Anatomia foliar de Eugenia brasiliensis Lam. (Myrtaceae) proveniente de áreas de restinga e de floresta. Rev Bras Farmacogn 17: 426-443.

Foster AS 1949. Practical plant anatomy. 2. ed. Princeton: D. Van Nostrand.

Gondim ANS, Oliveira VR, Silva LR, Silva BA, Conde-Garcia EA 2006. Complete atrioventricular block on isolated guinea pig heart induced by an aqueous fraction obtained from Psidium guajava L. leaf. Rev Bras Farmacogn 16: 312-316.

Gressler E, Pizo MA, Morellato LPC 2006. Polinização e dispersão de sementes em Myrtaceae do Brasil. Rev Bras Bot 29: 509-530.

Guo QM, Yang XW 2006. Cypellocarpin C and other compounds from the fruits of Eucalyptus globulus Labill. Biochem Syst Ecol 34: 543-545.

Haddad A. Obtenção e coloração de cortes semifinos. In: Souza W, Haddad A, Sesso A, Silveira M, Barth OM, Machado RD, Padrón TS 1989. Manual sobre técnicas básicas em microscopia eletrônica. Rio de Janeiro: Sociedade Brasileira de Microscopia Eletrônica.

Halliwell B, Gutteridge J, Aruoma O 1987. The deoxyribose method: a simple "test tube" assay for determination of rate constants for reaction of hydroxyl radicals. Anal Biochem 165: 215-219.

Hill KD, Johnson LAS 1995. Systematic studies in the eucalypts 7. A revision of the bloodwoods, genus Corymbia (Myrtaceae). Telopea 6: 185-504.

Hussein SAM, Hashim ANM, El-Sharawy RT, Seliem MA, Linscheid M, Lindequist U, Nawwar MAM 2007. Ericifolin: an eugenol 5-O-galloylglucoside and other phenolics from Melaleuca ericifolia. Phytochemistry 68: 1464-1470.

Jirovetz L, Bail S, Buchbauer G, Stoilova I, Krastanov A, Stoyanova A, Stanchev V, Schmidt E 2007. Chemical composition, olfactory evaluation and antioxidant effects of the leaf essential oil of Corymbia citriodora (Hook) from China. Nat Prod Comm 2: 599-606.

Johansen DA 1940. Plant microtechnique. New York: Mc Graw Hill Book.

Johnson ED 1926. A comparison of the juvenile and adult leaves of Eucalyptus globulus. New Phytol 25: 202-212.

Kreuger MRO, Ternes CE, Mello LL, Cruz AB, Leite SN, Tames DR 2007. The influence of the essential oil of Melaleuca alternifolia on the healing of infected dental alveoli: a histological study in rats. Rev Bras Farmacogn 17: 349355.

Lima IO, Oliveira RAG, Lima EO, Farias NMP, Souza EL 2006 Atividade antifúngica de óleos essenciais sobre espécies de Candida. Rev Bras Farmacogn 16: 197-201.

Luque R, Sousa HC, Kraus JE 1996. Métodos de coloração de Roeser (1972) modificado e de Kropp (1972) visando a substituição do azul de astra por azul de alcião 8GS ou 8GX. Acta Bot Bras 10: 199-211.

Medeiros KCP, Monteiro JC, Diniz MFFM, Medeiros IA, Silva BA, Piuvezam MR 2007. Effect of the activity of the Brazilian polyherbal formulation: Eucalyptus globulus Labill, Peltodon radicans Pohl and Schinus terebinthifolius Raddi in inflammatory models. Rev Bras Farmacogn 17: 23-28.

Medice R, Alves E, Assis RT, Magno Júnior RG, Lopes EAGL 2007. Óleos essenciais no controle da ferrugem asiática da soja Phakopsora pachyrhizi Syd. e P. Syd. Cien Agrotec 31: 83-90.

Metcalfe CR, Chalk L 1979. Anatomy of dicotyledons. 2. ed. Oxford: Claredon Press, v.1.

Migliato KF, Moreira RRD, Mello JCP, Sacramento LVS, Corrêa MA, Salgado HRN 2007. Controle da qualidade do fruto de Syzygium cumini (L.) Skeels. Rev Bras Farmacogn 17: 94-101.

Oliveira F, Akisue G 1997. Fundamentos de farmacobotânica. 2. ed. São Paulo: Atheneu.

Oliveira AM, Humberto MMS, Silva JM, Rocha RFA, Sant'Ana AEG 2006. Estudo fitoquímico e avaliação das atividades moluscicida e larvicida dos extratos da casca do caule e folha de Eugenia malaccensis L. (Myrtaceae). Rev Bras Farmacogn 16 (Supl.): 618-624.

Oliveira FQ, Gobira B, Guimarães C, Batista J, Barreto M, Souza M 2007. Espécies vegetais indicadas na odontologia. Rev Bras Farmacogn 17: 466-476.

Paula JAM, Paula JR, Bara MTF, Rezende MH, Ferreira HD 2008. Estudo farmacognóstico das folhas de Pimenta pseudocaryophyllus (Gomes) L.R. Landrum Myrtaceae. Rev Bras Farmacogn 18: 265-278.

Roeser KR 1972. Die Nadel der Schwarzkiefer Massenprodukt und Kunstwerk der Natur. Mikrokosmos 61: 33-36.

Sakai WS 1973. Simple method for differential staining of 
paraffin embedded plant material using toluidine blue $\mathrm{O}$. Stain Technol 48: 247-249.

Salvagnini LE, Oliveira JRS, Santos LE, Moreira RRD, Pietro RCLR 2008. Avaliação da atividade antibacteriana de folhas de Myrtus communis L. (Myrtaceae). Rev Bras Farmacogn 18: 241-244.

Sass JE 1951. Botanical microtechnique. 2. ed. Ames: Iowa State College.

Serafin C, Nart V, Malheiros A, Cruz AB, Monache FD, Gette MA, Zacchino S, Cechinel Filho V 2007. Avaliação do potencial antimicrobiano de Plinia glomerata (Myrtaceae) Rev Bras Farmacogn 17: 578-582.

Seyoum A, Palsson K, Kung'a S, Kabiru EW, Lwande W, Killeen GF, Hassanali A, Knols BGJ 2002. Traditional use of mosquito-repellent plants in western Kenya and their evaluation in semi-field experimental huts against Anopheles gambiae: ethnobotanical studies and application by thermal expulsion and direct burning. Trans R Soc Trop Med Hyg 96: 225-231.

Soffiatti P, Angyalossy-Alfonso V 1999. Estudo anatômico comparativo do lenho e da casca de duas espécies de Eugenia L. (Myrtaceae). Rev Bras Bot 22: 175-184.

Souza W 1998. Técnicas básicas de microscopia eletrônica aplicadas às Ciências Biológicas. Rio de Janeiro: Sociedade Brasileira de Microscopia Eletrônica.

Tuffi Santos LD, Sant'anna-Santos BF, Meira RMSA, Tiburcio RAS, Ferreira FA, Melo CAD, Silva EFS 2008. Danos visuais e anatômicos causados pelo glyphosate em folhas de Eucalyptus grandis. Planta Daninha 26: 9-16.

Wannes WA, Mhamdi B, Marzouk B 2008. Variations in essential oil and fatty acid composition during Myrtus communis var. italica fruit maturation. Food Chem 112: 621-626. 